\title{
Water holding capacity of Swamp Buffalo muscles raised with and without proper herd health $\mathbf{p}$
}

\author{
Fhaisol, M.A. ${ }^{1}$, Rosly, S. ${ }^{3}$, Nasyatul, E.M.H. ${ }^{3}$, Lokman, I. ${ }^{1}$, Hasliza A.H. ${ }^{1}$, Zamri, M.S. ${ }^{2}$, and \\ Zuki, A.B. ${ }^{1, *}$ \\ ${ }^{1}$ Dept. of Veterinary Preclinical Science, Faculty of Veterinary Medicine, Universiti Putra Malaysia \\ ${ }^{2}$ Dept. of Veterinary Laboratory Services, Faculty of Veterinary Medicine, Universiti Putra Malaysia \\ ${ }^{3}$ Livestock Science Research Centre, Malaysian Agricultural Research and Development Institute \\ (MARDI)
}

\begin{abstract}
Fresh meat is composed of $70-75 \%$ water. Meanwhile, water holding capacity (WHC) affects storage quality, appearance, eating experience, and also contributes to loss of profit for meat entrepreneurs. WHC is influenced by the species, sex, breed, farming practices, as well as post-slaughter storage and handling. Swamp buffalo meat is leaner compared to cattle, goats, and sheep. Therefore, this study aims to determine the WHC of swamp buffalo muscles raised with two herd health programs at different aging periods. A total of 24 months old male swamp buffalo $(n=4)$ was raised with a proper herd health protocol (HHP) and another $(n=6)$ without a proper herd health protocol (NHHP). The drip loss (DL), thawing loss (TL), and cooking loss (CL) for longissimus dorsi (LD), supraspinatus (SS), and semitendinosus (ST) muscles were evaluated on day 1, 7, and 14. Based on the results, only SS and ST from NHHP showed significant differences $(\mathrm{P} \leq 0.05)$, while DL, LD, SS, and ST of the HHP and NHHP also differed significantly $(\mathrm{P} \leq 0.05)$. Furthermore, the $\mathrm{TL}$ and $\mathrm{CL}$ for all the muscles showed significant differences $(\mathrm{P} \leq 0.05)$ at day 7 of aging in the NHHP group, while on day 14, both were significantly higher in LD and ST muscles of NHHP compared to the HHP group. Therefore, the results showed that the muscles of the HHP group had a better WHC compared to NHHP.
\end{abstract}

Keyword: Swamp buffalo, Herd Health Program, Water holding capacity

\section{Introduction}

The demand for beef is high due to the increasing purchasing power. Meanwhile, swamp buffalo is not only used for agricultural purposes but also as a protein source. However, the

*Corresponding author: zuki@upm.edu.my 
rearing system remains unchanged as over $95 \%$ are carried out in less extensive or semi-wild production systems [20] while $80 \%$ of the farmers utilize the animals as a source of power for work [45], characterized by a lack of proper herd health program [47].

In general, animals reared under an improper herd health program are susceptible to undesirable conditions such as diseases, drug residues, toxins, and often fail to meet consumer's expectations [23]. However, swamp buffalo reportedly adapt easily to a harsh environment $[10,19]$. Meanwhile, water holding capacity (WHC) is the ability of the meat to retain and absorb water [5] without the application of physical factors such as gravity, heat/cold or pressure [1]. It is one of the important meat qualities determined by the visual and sensory properties [41].

Rejections occur at the purchasing point when the meats do not meet the standard water holding capacity (WHC) [43], which is a complex attribute of meat [44]. In general, factors that affect WHC are either pre/post-slaughter [40], such as genetics and production system, or other processing factors during the meat production chain [16]. Furthermore, WHC has been explored in various animals, but studies on swamp buffalo are very limited. Therefore, this study aims to determine and compare the water holding capacity of swamp buffalo muscles raised with and without a proper herd health program at different aging periods.

\subsection{Materials and Methods}

\subsection{Animals}

Four male swamp buffaloes (Bubalus bubalis) raised under a proper herd health protocol (HHP), and six raised without a proper herd health protocol (NHHP) aged approximately 24 months old were used in this study. All the animals were slaughtered by the Department of Veterinary Services, Sabah. Furthermore, the meat samples from supraspinatus (SS), longissimus dorsi (LD), and semitendinosus (ST) muscles were collected and analyzed for drip, thawing, and cooking loss at day 1, 7, and 14 aging periods.

\subsection{Sampling process}

LD, SS, and ST were divided into three subgroups of $90 \mathrm{gm}$ each as triplicates. These muscles were further divided into three subgroups of $30 \mathrm{gm}$ each to evaluate drip, thawing, and cooking loss at days 1,7 , and 14 aging periods.

\subsection{Drip loss}

The drip loss (\%) was determined by placing the samples on the plastic mesh to prevent contact with the inflated polyethylene bag surface. These samples collected from the sampling process were kept in the refrigerator at $4^{\circ} \mathrm{C}$ for 24 hours (D1), D7 and D14, respectively. After the designated periods were completed, the samples were removed from 
the polyethylene bags, gently blotted dry and weighed [43]. The drip loss was calculated as the percentage of differences between the initial and final weight.

Drip loss $(\%)=\frac{W i-W f}{W i} X 100 \%$

Where;

$\mathrm{Wi}=$ Initial weight $(\mathrm{g})$

$\mathrm{Wf}=$ Final weight $(\mathrm{g})$

\section{$2.4 \quad$ Thawing loss}

To determine the thawing loss (\%), the samples obtained after the drip loss determination at various aging periods were frozen at $-20^{\circ} \mathrm{C}$ with wind flow at $2.6 \mathrm{~m} / \mathrm{s}$ [30] for seven days, and regularly inspected to ensure that freezing was achieved. The samples were then thawed at $4^{\circ} \mathrm{C}$ for 8 hours, removed from the polyethylene bag, gently blotted, and weighed [32]. The thawing loss was calculated based on the differences in the weight of the samples before frozen and thaw.

Thawing loss $(\%)=\frac{W i-W f}{W i} X 100 \%$

Where;

$\mathrm{Wi}=$ Initial weight $(\mathrm{g})$

$\mathrm{Wf}=$ Final weight $(\mathrm{g})$

\section{$2.5 \quad$ Cooking loss}

The cooking loss was determined based on a modified method of $[38,40]$. The meat samples were initially thawed, and a cooking thermometer (Testo 103, Lenzkirch, Germany) was inserted into the central core of the meat in the polyethylene bag. Furthermore, the samples were placed into a thermostatically controlled water bath (WTB 15, Beuchenbach, Germany) at boiling temperature for $20 \mathrm{~min}$ up to $75-77^{\circ} \mathrm{C}$ [34] and then immersed in a running tap for approximately $30 \mathrm{~min}$ [41]. The samples were then gently blotted dry without squeezing to remove exudate and weighed. The cooking loss was calculated using the formula:

Cooking loss $(\%)=\frac{W i-W f}{W i} X 100 \%$

Where;

Wi= Initial weight $(g)$

$W f=$ Final weight $(g)$

\subsection{Statistical Analysis}

Data analysis was performed using the two-way ANOVA followed by Tukey's Test for posthoc analysis. The significance level was set at $\mathrm{P} \leq 0.05$. 


\subsection{Results}

The drip loss increased significantly $(\mathrm{P} \leq 0.05)$ in the SS and ST of the NHHP group (Table 1). However, there were no significant differences $(\mathrm{P} \geq 0.05)$ in all the meat samples in the HHP group (Table 2). Furthermore, there were no significant differences $(\mathrm{P} \geq 0.05)$ in the drip loss of all muscle at various aging periods between HHP and NHHP. (Table 3, 4, and 5).

Table 1. Drip loss (\%) of meat samples from LD, SS, and ST at D1, D7, and D14 of aging in NHHP group.

\begin{tabular}{|c|c|c|c|c|}
\hline \multirow{2}{*}{ Meat } & \multicolumn{3}{|c|}{ Aging Period } & \multirow{2}{*}{ P-Value } \\
\cline { 2 - 3 } & Day 1 & Day 7 & Day 14 & \\
\hline LD & $1.57 \pm 0.51$ & $2.74 \pm 0.90$ & $3.16 \pm 0.30$ & 0.2047 \\
\hline SS & $2.07 \pm 0.54^{x}$ & $3.30 \pm 0.78^{y}$ & $5.38 \pm 0.99^{z}$ & 0.0302 \\
\hline ST & $2.58 \pm 0.54^{x}$ & $6.17 \pm 1.35^{y}$ & $6.08 \pm 1.07^{z}$ & 0.0438 \\
\hline P-Value & 0.4207 & 0.0722 & 0.071 & \\
\hline
\end{tabular}

$x y z$ Values within row are significantly different at $\mathrm{P} \leq 0.05$.

Table 2. Drip loss (\%) of meat samples from LD, SS, and ST at D1, D7, and D14 of aging in HHP group.

\begin{tabular}{|c|c|c|c|c|}
\hline \multirow{2}{*}{ Meat } & \multicolumn{3}{|c|}{ Aging Period } & \multirow{2}{*}{ P-Value } \\
\cline { 2 - 4 } & Day 1 & Day 7 & Day 14 & \\
\hline LD & $1.06 \pm 0.33$ & $3.14 \pm 0.19$ & $3.39 \pm 0.40$ & 0.12 \\
\hline SS & $1.37 \pm 0.52$ & $3.17 \pm 0.96$ & $5.81 \pm 0.54$ & 0.8157 \\
\hline ST & $3.86 \pm 1.49$ & $3.67 \pm 0.56$ & $6.19 \pm 1.69$ & 0.179 \\
\hline P-Value & 0.12 & 0.8157 & 0.179 & \\
\hline
\end{tabular}

Table 3. Drip loss (\%) of meat samples from HHP and NHHP groups at day 1 aging.

\begin{tabular}{|c|c|c|c|}
\hline \multirow{2}{*}{ Meat } & \multicolumn{2}{|c|}{ Buffalo Group } & \multirow{2}{*}{ P-Value } \\
\cline { 2 - 3 } & NHHP $(\mathrm{n}=6)$ & HHP $(\mathrm{n}=4)$ & \\
\hline LD & $1.57 \pm 0.51$ & $1.06 \pm 0.33$ & 0.4774 \\
\hline SS & $2.07 \pm 0.54$ & $1.37 \pm 0.52$ & 0.4025 \\
\hline ST & $2.58 \pm 0.54$ & $3.86 \pm 1.49$ & 0.3766 \\
\hline P-Value & 0.4207 & 0.12 & \\
\hline
\end{tabular}

Table 4. Drip loss (\%) of meat samples from HHP and NHHP groups at day 7 aging.

\begin{tabular}{|c|c|c|c|}
\hline \multirow{2}{*}{ Meat } & \multicolumn{2}{|c|}{ Buffalo Group } & \multirow{2}{*}{ P-Value } \\
\cline { 2 - 3 } & NHHP $(\mathrm{n}=6)$ & HHP $(\mathrm{n}=4)$ & \\
\hline LD & $2.74 \pm 0.90$ & $3.14 \pm 0.19$ & 0.7315 \\
\hline SS & $3.30 \pm 0.78$ & $3.17 \pm 0.96$ & 0.9211 \\
\hline ST & $6.17 \pm 1.35$ & $3.67 \pm 0.56$ & 0.1884 \\
\hline P-Value & 0.0722 & 0.8157 & \\
\hline
\end{tabular}


Table 5. Drip loss (\%) of meat samples from HHP and NHHP groups at day 14 aging.

\begin{tabular}{|c|c|c|c|}
\hline \multirow{2}{*}{ Meat } & \multicolumn{2}{|c|}{ Buffalo Group } & \multirow{2}{*}{ P-Value } \\
\cline { 2 - 3 } & NHHP $(\mathrm{n}=6)$ & HHP $(\mathrm{n}=4)$ & \\
\hline LD & $3.16 \pm 0.30$ & $3.39 \pm 0.40$ & 0.6516 \\
\hline SS & $5.38 \pm 0.99$ & $5.81 \pm 0.54$ & 0.755 \\
\hline ST & $6.08 \pm 1.07$ & $6.19 \pm 1.69$ & 0.9573 \\
\hline P-Value & 0.071 & 0.179 & \\
\hline
\end{tabular}

The thawing loss of meat samples from LD increased according to the aging period, while the SS and ST decreased in the NHHP group, although both results were not significantly different $(\mathrm{P} \geq 0.05)$. However, there were significant differences at $\mathrm{D} 14$ for all the muscles (LD, SS and ST) of the NHHP group (Table 6). In the HHP group, the thawing loss of the SS muscle showed significant difference $(\mathrm{P} \leq 0.05)$ with increasing aging time. All the muscle (LD, SS and ST) also showed significant differences at D14. (Table 7)

Table 6. Thawing loss of the meat from LD, SS, and ST at D1, D7, and D14 aging period in NHHP group of swamp buffalo.

\begin{tabular}{|c|c|c|c|c|}
\hline \multirow{2}{*}{ Meat } & \multicolumn{3}{|c|}{ Aging Period } & \multirow{2}{*}{ P-Value } \\
\cline { 2 - 4 } & Day 1 & Day 7 & Day 14 & \\
\hline LD & $5.80 \pm 1.20$ & $5.67 \pm 2.21$ & $10.29 \pm 1.83^{a}$ & 0.1521 \\
\hline SS & $4.42 \pm 1.32$ & $5.78 \pm 0.60$ & $4.37 \pm 0.79^{b}$ & 0.5076 \\
\hline ST & $5.97 \pm 0.56$ & $5.37 \pm 0.53$ & $4.52 \pm 0.76^{c}$ & 0.2857 \\
\hline P-Value & 0.552 & 0.9754 & 0.0054 & \\
\hline
\end{tabular}

$a, b, c$ Values within column are significantly different at $\mathrm{P} \leq 0.05$.

Table 7. Thawing loss of the meat from LD, SS, and ST at D1, D7, and D14 aging period in HHP group of swamp buffalo.

\begin{tabular}{|c|c|c|c|c|}
\hline \multirow{2}{*}{ Meat } & \multicolumn{3}{|c|}{ Aging Period } & \multirow{2}{*}{ P-Value } \\
\cline { 2 - 4 } & Day 1 & Day 7 & Day 14 & 0.7564 \\
\hline LD & $5.18 \pm 1.66$ & $4.26 \pm 1.39$ & $3.77 \pm 0.78^{a}$ & 0.0044 \\
\hline SS & $4.47 \pm 0.99^{x}$ & $5.77 \pm 0.33^{y}$ & $2.08 \pm 0.49^{b, z}$ & 0.5836 \\
\hline ST & $6.07 \pm 0.87$ & $4.22 \pm 1.16$ & $5.70 \pm 1.71^{c}$ & \\
\hline P-Value & 0.634 & 0.3872 & 0.0066 & \\
\hline
\end{tabular}

$a, b, c$ Values within column are significantly different at $\mathrm{P} \leq 0.05$.

$x, y, z$ Values within row are significantly different at $\mathrm{P} \leq 0.05$.

There were no significant differences $(\mathrm{P} \geq 0.05)$ in the thawing loss for all muscle of both HHP and NHHP groups at D1 and D7 (Tables 8 and 9), but at D14, the entire muscles (LD, SS and ST) in both HHP and NHHP groups showed significant differences $(\mathrm{P} \leq 0.05)$. Furthermore, the thawing loss of LD and SS muscles in the NHHP was more significant $(\mathrm{P} \leq 0.05)$ compared to the HHP group (Table 10). 
Table 8. Thawing loss (\%) of the meat from LD, SS, and ST in HHP and NHHP groups of swamp buffalo at D1 aging.

\begin{tabular}{|c|c|c|c|}
\hline \multirow{2}{*}{ Meat } & \multicolumn{2}{|c|}{ Buffalo Group } & \multirow{2}{*}{ P-Value } \\
\cline { 2 - 3 } & NHHP $(\mathrm{n}=6)$ & HHP $(\mathrm{n}=4)$ & \\
\hline LD & $5.80 \pm 1.20$ & $5.18 \pm 1.66$ & 0.7629 \\
\hline SS & $4.42 \pm 1.32$ & $4.47 \pm 0.99$ & 0.9787 \\
\hline ST & $5.97 \pm 0.56$ & $6.07 \pm 0.87$ & 0.9244 \\
\hline P-Value & 0.552 & 0.634 & \\
\hline
\end{tabular}

Table 9. Thawing loss (\%) of the meat from LD, SS, and ST in HHP and NHHP groups of swamp buffalo at D7 aging.

\begin{tabular}{|c|c|c|c|}
\hline \multirow{2}{*}{ Meat } & \multicolumn{2}{|c|}{ Buffalo Group } & \multirow{2}{*}{ P-Value } \\
\cline { 2 - 3 } & NHHP $(\mathrm{n}=6)$ & $\operatorname{HHP}(\mathrm{n}=4)$ & 0.648 \\
\hline LD & $5.67 \pm 2.21$ & $4.26 \pm 1.39$ & 0.9828 \\
\hline SS & $5.78 \pm 0.60$ & $5.77 \pm 0.33$ & 0.3403 \\
\hline ST & $5.37 \pm 0.53$ & $4.22 \pm 1.16$ & \\
\hline P-Value & 0.9754 & 0.3872 & \\
\hline
\end{tabular}

Table 10. Thawing loss (\%) of the meat from LD, SS, and ST in HHP and NHHP groups of swamp buffalo at D14 of aging.

\begin{tabular}{|c|c|c|c|}
\hline \multirow{2}{*}{ Meat } & \multicolumn{2}{|c|}{ Buffalo Group } & \multirow{2}{*}{ P-Value } \\
\cline { 2 - 3 } & NHHP $(\mathrm{n}=6)$ & HHP $(\mathrm{n}=4)$ & 0.0248 \\
\hline LD & $10.29 \pm 1.83^{a, x}$ & $3.77 \pm 0.78^{a, y}$ & 0.0334 \\
\hline SS & $4.37 \pm 0.79^{b, x}$ & $2.08 \pm 0.49^{b, y}$ & 0.4941 \\
\hline ST & $4.52 \pm 0.76^{c}$ & $5.70 \pm 1.71^{c}$ & \\
\hline P-Value & 0.0054 & 0.0066 & \\
\hline
\end{tabular}

$a, b, c$ Values within column are significantly different at at $\mathrm{P} \leq 0.05$.

${ }^{x y}$ Value within row are significantly different at $\mathrm{P} \leq 0.05$.

The cooking loss $(\%)$ of the meat samples from LD, SS, and ST in the NHHP and HHP groups at different aging periods is shown in Table 11 and 12. In the NHHP group, the cooking loss (\%) was highest at D7, followed by D14 and lowest at D1 for all the muscle samples (Table 11). Meanwhile, only the SS muscle differed significantly in all the three aging periods of NHHP (Table 11), but not in the HHP group (Table 12).

A comparison of the cooking loss between HHP and NHHP groups is shown in Table 13, 14 , and 15. Only the SS muscle differed significantly $(\mathrm{P} \leq 0.05)$ throughout all the aging periods in the NHHP (Table 11) but not in the HHP group. The cooking loss (\%) between NHHP and HHP differed only at D7 and D14 (Table 14 and Table15), while the value of water loss was significantly significant $(\mathrm{P} \leq 0.05)$ in NHHP compared to the HHP group (Table 14 and 15). 
Table 11. Cooking loss (\%) of meat samples from the LD, SS, and ST in NHHP group of swamp buffalo at different aging period.

\begin{tabular}{|c|c|c|c|c|}
\hline \multirow{2}{*}{ Muscle } & \multicolumn{3}{|c|}{ Aging Period } & \multirow{2}{*}{ P-Value } \\
\cline { 2 - 4 } & Day1 & Day 7 & Day 14 & \\
\hline LD & $19.93 \pm 3.65$ & $30.51 \pm 1.32$ & $25.23 \pm 2.09$ & 0.0826 \\
\hline SS & $26.42 \pm 2.08 \mathrm{x}$ & $33.73 \pm 1.82 \mathrm{y}$ & $29.60 \pm 1.23 \mathrm{z}$ & 0.0111 \\
\hline ST & $24.80 \pm 3.24$ & $33.32 \pm 3.62$ & $30.27 \pm 1.56$ & 0.0704 \\
\hline
\end{tabular}

$x y$ Value within row are significantly different at $\mathrm{P} \leq 0.05$.

Table 12: Cooking loss (\%) of meat samples from the LD, SS, and ST in HHP group of swamp buffalo at different aging period.

\begin{tabular}{|c|c|c|c|c|}
\hline \multirow{2}{*}{ Muscle } & \multicolumn{3}{|c|}{ Aging Period } & P-Value \\
\cline { 2 - 5 } & Day1 & Day 7 & Day 14 & \\
\hline LD & $21.93 \pm 3.30$ & $22.37 \pm 0.79$ & $16.52 \pm 1.70$ & 0.1592 \\
\hline SS & $25.95 \pm 3.12$ & $27.50 \pm 1.60$ & $25.24 \pm 6.98$ & 0.6773 \\
\hline ST & $28.17 \pm 3.69$ & $24.25 \pm 3.69$ & $20.34 \pm 2.63$ & 0.2372 \\
\hline
\end{tabular}

Table 13. Cooking loss (\%) of meat samples from the LD, SS, and ST in NHHP and HHP groups of swamp buffalo at D1 aging.

\begin{tabular}{|c|c|c|c|}
\hline \multirow{2}{*}{ Muscle } & \multicolumn{2}{|c|}{ Buffalo Group } & \multirow{2}{*}{ P-Value } \\
\cline { 2 - 3 } & NHHP $(\mathrm{n}=6)$ & HHP $(\mathrm{n}=4)$ & 0.7603 \\
\hline LD & $19.93 \pm 3.65$ & $21.93 \pm 3.30$ & 0.7986 \\
\hline SS & $26.42 \pm 2.08$ & $25.95 \pm 3.12$ & 0.7546 \\
\hline ST & $24.80 \pm 3.24$ & $28.17 \pm 3.69$ & \\
\hline P-value & 0.5835 & 0.2149 & \\
\hline
\end{tabular}

Table 14. Cooking loss (\%) of meat samples from the LD, SS, and ST in NHHP and HHP groups of swamp buffalo at D7 aging.

\begin{tabular}{|l|c|c|c|}
\hline \multirow{2}{*}{ Muscle } & \multicolumn{2}{|c|}{ Buffalo Group } & \multirow{2}{*}{ P-Value } \\
\cline { 2 - 3 } & NHHP (n=6) & HHP $(\mathrm{n}=4)$ & 0.0004 \\
\hline LD & $30.51 \pm 1.32^{x}$ & $22.37 \pm 0.79^{y}$ & 0.0154 \\
\hline SS & $33.73 \pm 1.82^{x}$ & $27.50 \pm 1.60^{y}$ & 0.0361 \\
\hline ST & $33.32 \pm 3.62^{x}$ & $24.25 \pm 3.69^{y}$ & \\
\hline & 0.4323 & 0.1782 & \\
\hline
\end{tabular}

${ }^{x y}$ Value within row are significantly different at $\mathrm{P} \leq 0.05$.

Table 15. Cooking loss (\%) of meat samples from the LD, SS, and ST in NHHP and HHP groups of swamp buffalo at D14 aging.

\begin{tabular}{|c|c|c|c|}
\hline \multirow{2}{*}{ Muscle } & \multicolumn{2}{|c|}{ Buffalo Group } & \multirow{2}{*}{ P-Value } \\
\cline { 2 - 3 } & NHHP $(\mathrm{n}=6)$ & $\operatorname{HHP}(\mathrm{n}=4)$ & 0.0127 \\
\hline LD & $25.23 \pm 2.09 \mathrm{x}$ & $16.52 \pm 1.70 \mathrm{y}$ & 0.02667 \\
\hline SS & $29.60 \pm 1.23 \mathrm{x}$ & $25.24 \pm 6.98 \mathrm{y}$ & 0.0024 \\
\hline ST & $30.27 \pm 1.56 \mathrm{x}$ & $20.34 \pm 2.63 \mathrm{y}$ & \\
\hline P-value & 0.2938 & 0.5157 & \multicolumn{2}{|c}{} \\
\hline
\end{tabular}

${ }^{x y}$ Value within row are significantly different at $\mathrm{P} \leq 0.05$. 


\subsection{Discussion}

Fresh meat is generally composed of $70-75 \%$ of water [30]. Meanwhile, there are three attributes of water holding capacity that primarily affects meat quality namely drip, thawing, and cooking loss which are in turn influenced by pre/post-slaughter factors, as well as storage, and processing of meat. Pre-slaughter factors such as farming system and stress management under a proper herd health program are essential to ensure good water holding capacity. Furthermore, proper herd health promotes appropriate feeding and welfare management systems to sustain the physiological needs of the animals. [28] The results showed that differences in the diet supplied as part of the herd health program to the swamp buffalo produced different drip loss values. [15]. Aside from diet, sex also constitutes one of the most critical factors which affect drip WHC in meat [4]. However, this variable was not investigated in this study.

The results showed that the drip loss increased with aging, but there was no significant difference in all muscles of the NHHP and HHP groups. This is presumably due to the quantity of glycogen reserves which is strongly associated with glycolysis during the conversion of muscle to meat. [27, 28]. Furthermore, management systems without a proper herd health program are associated with nutrient imbalance and low glycogen reserves which leads to unnatural $\mathrm{pH}$ value of the meat. Based on previous studies, the water holding capacity (WHC) value ranges from 2.60 to $4.0 \%$ [8] depending on the species, sex, as well as pre/post-slaughter handling [13]. The differences in thawing and cooking loss percentages between the two groups were also strongly associated with meat storage and processing [25].

The processing factors include lateral and transverse shrinkages of myofibril at rigor [14], membrane permeability to water development of drip channel [48] and extracellular space [33], as well as post-mortem cytoskeletal protein degradation due to aging [26]. Therefore, significant differences in thawing and cooking loss were found in meat samples from SS (muscle of forelimb) and ST (muscle of hindlimb) of NHHP and HHP groups at D14. This is also supported by [7] which reported that aging influenced meat characteristics in all muscle samples. In contrast, [6] reported that there was no difference in WHC among the aging period, except in females [34]. The changes caused by aging differ from one muscle to another based on the location and fiber type which directly influence genetics, hormone, diet, and environmental factors $[24,31]$. In addition, it is also affected by the method used in the freezing or thawing process $[13,34]$

The freezing and thawing processes are important in preserving meat quality. Various methods are used to thaw meat, thereby producing different outcomes [11 17]. However, these methods have attracted several concerns as $[12,34]$ reported that aging and thawing do not affect WHC, while [3,22] stated otherwise. This is probably due to differences in samples and methods used $[22,36]$. Furthermore, despite using a similar method, the results in this study showed higher percentages of thawing loss compared to [2], which ranged between $1.00-2.5 \%$. However, the range obtained in this study is similar to [17].

Discrepancies associated with muscle type, sex, age of the animal or preservation techniques [46] lead to crystallization and protein denaturation during the aging process [29]. Furthermore, the difference in thawing loss percentage was due to the microstructure and protein structural changes as suggested by $[35,37]$. The application of aging and freeze-thaw practice leads to the massive destruction of meat quality through enzymatic proteolysis and 
ice crystal formation with the simultaneous release of lysosome [7] and disarray of the muscle fibers [21].

The cooking loss percentages also increased with aging periods as previously reported by $[18,42]$. In addition, the aging treatment also had a strong effect on water loss (39), while the muscle quality was also influenced by different thawing methods [9]. This result is slightly against [25], which suggested that longer storage time increases the thawing loss but reduces cooking loss. Furthermore, muscles' physiological and anatomical differences also affect the water holding capacity of meat $[34,44]$.

\subsection{Conclusion}

In general, swamp buffalo raised under a proper herd health program have higher WHC compared to others raised otherwise. Based on the results, the various types of swamp buffalo muscles raised with and without a proper herd health program at different aging periods produced specific outcomes.

\section{References}

[1] E. Puolanne and M. Halonen, Meat Sci. 86, 151 (2010).

[2] V. V. Chandirasekaran, G. Thulasi, J. Food Technol. 8, 239 (2010).

[3] X. L. Yu, X. B. Li, L. Zhao, X. L. Xu, H. J. Ma, G. H. Zhou, and J. A. Boles, J. Muscle Foods 21, 177 (2010).

[4] Y. Zhang, L. Zan, H. Wang, Y. Xin, and C. M. Adoligbe, African J. Biotechnol. 9, 4504 (2010).

[5] K. L. Pearce, K. Rosenvold, H. J. Andersen, and D. L. Hopkins, Meat Sci. 89, 111 (2011).

[6] H. Degens and M. T. Korhonen, Maturitas 73, 197 (2012).

[7] C. Leygonie, T. J. Britz, and L. C. Hoffman, Meat Sci. 91, 93 (2012).

[8] S. Traore, L. Aubry, P. Gatellier, W. Przybylski, D. Jaworska, K. Kajak-Siemaszko, and V. Santé-Lhoutellier, Meat Sci. 90, 917 (2012).

[9] X. Xia, B. Kong, J. Liu, X. Diao, and Q. Liu, LWT - Food Sci. Technol. 46, 280 (2012).

[10] M. Wanapat and S. Kang, Buffalo Bull. 32, 1 (2013).

[11] S. Akhtar, M. I. Khan, and F. Faiz, Pakistan J. Food Sci. 23, 198 (2013).

[12] Y. B. Kim, S. K. Ku, J. W. Jeong, E. M. Kim, J. D. Park, and A. Jang, Korean J. Food Sci. Anim. Resour. 33, 23 (2013).

[13] A. L. Grayson, D. A. King, S. D. Shackelford, M. Koohmaraie, and T. L. Wheeler, J. Anim. Sci. 92, 2735 (2014).

[14] J. M. Hughes, S. K. Oiseth, P. P. Purslow, and R. D. Warner, Meat Sci. 98, 520 (2014).

[15] C. Lambertz, P. Panprasert, W. Holtz, E. Moors, S. Jaturasitha, M. Wicke, and M. Gauly, Asian-Australasian J. Anim. Sci. 27, 551 (2014).

[16] J. M. Lorenzo, S. Crecente, D. Franco, M. V. Sarriés, and M. Gómez, Animal 8, 494 (2014).

[17] M. H. Rahman, M. M. Hossain, S. M. E. Rahman, M. A. Hashem, and D. H. Oh, Korean J. Food Sci. Anim. Resour. 34, 482 (2014).

[18] R. D. A. Warner, M. B. Kerr, Y. H. B. C. Kim, and G. D. Geesink, Anim. Prod. Sci. 494 (2014).

[19] Werner, P., edited by H. Prins \& I. Gordon (Cambridge University Press, 2014), pp. 452-496.

[20] L. C. Cruz, (Universitas Halo Oleo, Kendari, Southeast Sulawesi, 2015), pp. 15-37.

[21] D. L. Glanc, C. P. Campbell, J. Cranfield, K. C. Swanson, and I. B. Mandell, Can. J. Anim. Sci. 95, 37 (2015).

[22] V. Tomović, S. Stajić, M. Jokanović, N. Stanišić, and D. Živković, Meso XVII, 455 (2015). 
[23] W. M. Hilton, https://www.msdvetmanual.com/management-and-nutrition/healthmanagement-interaction-beef-cattle/beef-quality-assurance-and-beef-safety-programs\#.(2015)

[24] J. B. A. Listrat, B. Lebret, I. Louveau, T. Astruc, M. Bonnet, L. Lefaucheur, B. Picard, Sci. World J. 2016, 1 (2016).

[25] C. N. Aroeira, R. A. Torres, P. Rogério, L. Alberto, M. Gomide, A. L. S. Ramos, M. M. Ladeira, and E. M. Ramos, Meat Sci. 116, 118 (2016).

[26] C. J. Contreras-Castillo, D. Lomiwes, G. Wu, D. Frost, and M. M. Farouk, Meat Sci. 113, 65 (2016)

[27] E. M. England, S. K. Matarneh, E. M. Oliver, A. Apaoblaza, T. L. Scheffler, H. Shi, and D. E. Gerrard, Meat Sci. 114, 95 (2016).

[28] D. J. Mellor, Animals 6, 1 (2016).

[29] P. P. Purslow, S. Oiseth, J. Hughes, and R. D. Warner, Food Res. Int. 89, 739 (2016).

[30] Y. Choi, K. Hwang, T. Jeong, Y. Kim, K. Jeon, E. Kim, J. Sung, H. Kim, and C. Kim, Korean J. Food Sci. An. 36, 1 (2016).

[31] A. P. Moloney and M. McGee, edited by F. Toldrá, 8th ed. (Woodhead Publishing, Cambridge, Kidlington, 2017), pp. 19-47.

[32] H. W. and Kim and Y. H. B. Kim, Asian-Australasian J. Anim. Sci. 30, 254 (2017).

[33] H.C. Bertram, edited by P.P. Purslow (Woodhead Publishing, Duxford, UK, 2017), pp. 380 396.

[34] H. W. and Kim and Y. H. B. Kim, Asian-Australasian J. Anim. Sci. 30, 254 (2017).

[35] R. D. Warner, in Lawrie's Meat Science: Eighth Edition (Elsevier Ltd, 2017), pp. 419-459.

[36] R. De Almeida, T. Filho, H. P. Cazedey, P. R. Fontes, A. De Lemos, S. Ramos, and E. M. Ramos, J. Food Qual. 2017, (2017).

[37] M. Zhang, F. Li, X. Diao, B. Kong, and X. Xia, Meat Sci. 133, 10 (2017).

[38] D. T. Utama, K. H. Baek, H. S. Jeong, S. K. Yoon, S. Joo, and S. K. Lee, Asian Australas. J. Anim. Sci. 31, 293 (2018).

[39] T. Daszkiewicz, D. Kubiak, and A. Panfil, J. Food Qual. 2018, 1 (2018).

[40] R. Fabre, G. Dalzotto, F. Perlo, P. Bonato, G. Teira, and O. Tisocco, Meat Sci. 138, 10 (2018).

[41] J. Hughes, F. Clarke, P. Purslow, and R. Warner, Meat Sci. 145, 1 (2018).

[42] R. S. B. Pinheiro, C. L. Francisco, D. M. Lino, and H. Borba, Meat Sci. 148, 72 (2019).

[43] A. Reiche, J. Oberson, P. Silacci, J. Messadène-chelali, H. D. Hess, and F. Dohme-meier, Meat Sci. 158, 107892 (2019).

[44] T. Xing, F. Gao, R. K. Tume, G. Zhou, and X. Xu, Compr. Rev. Food Sci. Food Saf. 18, 380 (2019).

[45] Yaemkong, S., Sarakul, M., Nguyen Ngoc, T., Buffalo Bull. 38, 99 (2019).

[46] C. Leygonie and L. C. Hoffman, Foods 9, 1624 (2020).

[47] S. Z. R. Suit-B, Yong, Latiffah Hassan, Steven Eric Krauss and Ooi, Peck Toung, Abd Rahaman Yasmin and Jonathan Epstein, Vet. Sci. 7, 27 (2020).

[48] Z. Ding, Q. Wei, C. Zhang, H. Zhang, and F. Huang, Food Chem. 340, 127914 (2021). 